\title{
Monarquía y alta nobleza: la consumación del asalto Borja al maes- trazgo de la Orden de Montesa (1545)*
}

\author{
Fernando Andrés Robres \\ Universidad Autónoma de Madrid \\ fernando.andres@uam.es
}

RESUMEN: La familia Borja consiguió hacerse con el maestrazgo de Montesa en 1545. Fracasó en consecuencia un nuevo intento de incorporación de la orden militar valenciana cuando ya lo habian sido las castellanas. Jugaron la partida personajes ciertamente ilustres: Carlos $V$, por entonces en los Países Bajos; el príncipe regente Felipe; el pontífice Paulo III -Alejandro Farnesio-, con quien aquéllos mantuvieron siempre una relación tensa; Francisco de los Cobos; el virrey de Valencia, duque de Calabria, segundo esposo de la reina Germana de Foix; Pedro de la Gasca, visitador entonces de aquel Reino y más tarde presidente de la Audiencia de Lima; y el IV duque de Gandía, Francisco, el después jesuita y santo, que contó con la ayuda de su esposa y de su madre. Ganaron los Borja. Una amplia base documental, sobre todo epistolar, permite reconstruir un episodio que bien puede ilustrar los problemas de la construcción de las nuevas estructuras políticas en la temprana época moderna, en concreto el difícil deslinde de poder entre la monarquía y la alta nobleza.

\section{Palabras Clave: Orden de Montesa; Órdenes Militares; Reino de Va- lencia; Siglo XVI; Familia Borja; Estado Moderno.}

* Proyecto de investigación financiado por el Ministerio de Economía y Competitividad con referencia HAR2014-53298-C2-2-P («Nuevas perspectivas de historia social en la ciudad de Madrid y sus áreas de influencia en la época moderna»). Siglas utilizadas: Archivo General de Simancas (AGS); Archivo Histórico Nacional (AHN); OOMM (sección de Órdenes Militares); Biblioteca Nacional de España (BNE). 


\section{Monarchy and Higher Nobility: The Final Assault of the Borgias on the Order of Montesa (1545)}

ABSTRACT: The Borgia family obtained the maestrazgo (mastership) of the Order of Montesa in 1545. This meant yet another failure in the Crown's attempt to incorporate the Valencian military order, as it had done previously with its Castilian counterparts. The players at this table included some very famous figures: Charles $V$, then in the Netherlands; the regent Prince Philip; Pope Paul III - Alessandro Farnese- who had always strained relations with Charles and Philip; Francisco de los Cobos; the Duke of Calabria, Viceroy of the Kingdom of Valencia and the second husband of the former Queen Germana de Foix; Pedro de la Gasca, then royal inspector of the Kingdom and later president of the Audiencia (Appeals Court) of Lima; and the fourth Duke of Gandia, Francisco, later both a Jesuit and a saint, who also enlisted the help of his wife and his mother. The Borgias won. An extensive collection of documents, particularly correspondence, makes it possible to reconstruct an episode that illustrates well not only the difficulties of constructing new political structures in the early modern period, but also the uncertain demarcation of power between the monarchy and the nobility.

KEY WORDS: Order of Montesa; Military Orders; Kingdom of Valencia; XVI ${ }^{\text {th }}$ Century; Borgia Family; Early Modern State.

La elección de maestre que tuvo lugar en el castillo-convento de la orden de Montesa el sábado 5 de abril de 1544 tras la muerte de frey don Francisco Llançol de Romaní, decimotercero en el orden, pasa por haber sido la más conflictiva de la historia de la institución. Tanto que, tras un agotador capítulo - de entre quince y dieciocho horas-, habrían salido los electores «ajados y desmayados sin Maestre, porque eligieron dos» ${ }^{1}$. Se trataba de frey don Guerau Bou, caballero anciano y a la sazón clavero de la Orden - tercera dignidad tras el maestre y el comendador mayor-, que habría obtenido veinticuatro votos, y don Pedro Luis Galcerán de Borja Castro-Pinós, que cosechó solo veintiuno pero que resultaría a la postre investido, como es sabido, como decimocuarto y último maestre de la orden militar valenciana ${ }^{2}$. La contienda entre dos aspirantes en el interior de la institución no era, además, sino la fa-

1 SAMPER, 1669, vol. II: 548.

2 La bibliografía sobre este último personaje es muy amplia. Una biografía sucinta, ANDRÉS ROBRES, 2010. Además de por la dignidad de maestre, ha alcanzado celebridad desde otros dos frentes: el de virrey en Orán y Mazalquivir, glosado en una crónica de la época que cuenta con edición reciente (SUÁREZ MONTANÉS, 2005; véase en particular el apartado de la introducción que le dedican M. Á. de Bunes y B. Alonso: 23-36); y el de reo de la inquisición que tratara hace ya algunos años CARRASCO, 1985: 195-204. 
chada de otro conflicto más trascendente, en el que una renombrada familia aristocrática disputó, con la ayuda de Roma - y con éxito-, el maestrazgo de Montesa a la monarquía de España en fecha tan avanzada.

Desde comienzos del segundo cuarto del siglo XVI — si no antes-, los Borja, la célebre familia setabense de los dos pontífices y el ducado de Gandía, ya para entonces una de las más importantes casas nobiliarias del Reino de Valencia, había hecho del maestrazgo de Montesa su objetivo, como lo hizo de otras sinecuras, sobre todo eclesiásticas ${ }^{3}$. No parecían ya los tiempos propicios para semejante pretensión, una vez consumada la incorporación a la Corona de las órdenes castellanas y cuando, obviamente, la monarquía propugnaba un estatus similar para Montesa. El control de la corporación revestía, desde luego, suma importancia: su territorio constituía el más extenso señorío del Reino de Valencia; la renta maestral podía estimarse para entonces en más de cinco mil ducados; ${ }^{4}$ y en sus filas militaba una veintena larga de caballeros pertenecientes a diversas familias de la nobleza regnícola que se repartían los frutos de la docena de encomiendas con que contaba la institución ${ }^{5}$. Pero los hechos se encargarían de demostrar que las tendencias de determinados procesos, en este caso la reordenación de las relaciones entre la alta nobleza y la monarquía en un momento crucial en la conformación de las nuevas estructuras políticas características de los tiempos modernos, distaron de comportarse de manera lineal.

La estrategia para situar Montesa en la órbita de la casa de Borja había conocido avances y retrocesos hasta llegar a concretarse en la elección de 1544. La condujo el III duque, don Juan de Borja y Enríquez (1494-1543), consciente de la relevancia que el maestrazgo tenía: «la qual dignitat, en aquest regne, axi en calitat com en renda, es molt important e principal». Sabía también que rendía una buena renta. Y no ocultaba que el objetivo se perseguía en clave familiar ${ }^{6}$. El duque maniobró primero en Roma aprovechando el ascenso al papado de Alejandro Farnesio (Paulo III), de quien obtuvo directamente - y a espaldas de la Orden - el nombramiento de su hijo Enrique de

3 Como, por ejemplo, de un rico monasterio cisterciense valenciano, al que accedieron varios de sus miembros: véase HISTORIA CRONOLÓGICA..., 2004: 46-47, 53 y 56-58. Para los Borja arzobispos de Valencia, que fueron todavía más, pueden encontrarse bastantes pistas en CALLADO ESTELLA, 1 (Valencia, 2013).

4 ANDRÉS ROBRES, 2014b: 478.

5 Diecinueve caballeros profesos estuvieron presentes en el Capítulo General que celebró la orden en 1537: Frey Miguel Beltrán y Peris, Libro de las visitas, capitulos generales, bullas apostólicas y otras cosas tocantes a la orden de Montesa, 1633; BNE, ms. 845: 88.

6 «[...] y no sols ab aquella [renta: la del maestrazgo] pot molt honrradament viure [su hijo Enrique, el primer candidato Borja a la dignidad, como vamos a ver], pero encara pot subvenir e ajudar a sos germans en moltes coses»: Juan de Borja, testamento; Gandía, 1529: Monumenta Borgia I: 26. Del mismo documento y cláusula procede la anterior cita en el texto. 
Borja y Aragón, de diecisiete años, como comendador mayor de Montesa (1535). Aunque, protestada la artimaña en el seno de la institución, el joven pretendiente y su mentor fracasaron en el primer intento de acceder al maestrazgo en la elección de 1537 en que resultó designado Llançol de Romaní. Eso sí: el revés lo fue solo relativo, porque el flamante maestre nombró de inmediato - y de nuevo: debió de mediar un pacto- a Enrique comendador mayor, esta vez con la aquiescencia de los miembros de la institución, lo que le colocaba inmejorablemente para la siguiente elección. Sin embargo, otro paso atrás o debilitamiento de la posición tuvo lugar cuando la promoción del propio Enrique a cardenal (1539) - había muerto un hermano que lo era, Rodrigo, y corrió el turno - obligó, en una especie de efecto dominó, a traspasar su empleo y supuestos derechos en Montesa a su medio hermano Pedro Luis Galcerán, niño entonces de doce años. Y vendrían a complicar todavía más las cosas a los Borja otras dos muertes. En 1543 nada menos que la del titular del ducado, lo que obligó a tomar las riendas de la casa a Francisco de Borja - después santo-, novel IV duque (debió compartirlas con la muy activa «triste duquesa de Gandía», como le gustaba firmar a doña Francisca de Castro, su madrastra). Y en 1544 la del maestre Llançol, también inesperada, lo que significaba que Francisco apenas se había podido hacer cargo de la situación y —quizá más importante - que el candidato Borja seguía siendo menor de edad ${ }^{7}$.

$* * *$

El episodio sobre el que va a ponerse el foco no es desconocido. Contamos para empezar, obligadamente, con la versión de Samper, el cronista de Montesa por excelencia, que la limita al enfrentamiento entre los dos caballeros candidatos. Refiere frey Hipólito la extraordinaria tensión vivida en el capítulo de 1544 y en las semanas siguientes, al disputarse las partes enfrentadas el gobierno, administración y rentas del maestrazgo sede vacante: deberemos volver sobre ello. También que «al otro día de las elecciones, que fue Domingo a 6 de Abril, ambos Eletos cuydaron de despachar sus procuradores a Roma para que Su Santidad mandasse decidir esta causa». Casi año y medio tardó en resolverse. Lo habría hecho, desde la misma fuente, de esta sencilla manera: "Mas en medio de este litigio hubo en este Reyno tales tratadores que consiguieron de el Clavero que cediera a su pretensión y el derecho que tenía al maestrado», justificando la actitud de Bou en motivos personales: como quiera que «era ya persona anciana, quiso salir de la confusión en que estaba y vivir con quietud lo que le quedaba de vida, y así cedió su derecho en

7 Mayor detalle de esos antecedentes en ANDRÉS ROBRES, 2014a: passim. 
19 Setiembre $1545 »^{8}$. Explicación que se antoja superficial y, por ello, insatisfactoria, todavía más cuando conocemos que el propio Samper consideraba que el «maestre conventual» legítimo, en tanto que candidato más votado en «elección canónica», debería haber sido frey Guerau, como afirma expresamente en otro lugar de su obra.

Alguna luz más se ha arrojado en los últimos tiempos, bien que diluida en monografías sobre temas diversos. Teodoro Hampe encontró un muy interesante informe de Pedro de la Gasca, entonces visitador real del Reino de Valencia, en el que exponía la conveniencia de aprovechar la ocasión —el enfrentamiento en el interior de la Orden- para incorporarla a la Corona ${ }^{9}$, pretensión que tampoco era nueva, pues se documentan intentos desde Fernando el Católico ${ }^{10}$. Un peldaño más supuso la aportación de Josep Martí Ferrando, que añadió a ese texto algunos otros hallados en documentación oficial de los archivos de Simancas y del Reino de Valencia, lo que le permitió esbozar una sucinta aproximación de lo ocurrido ${ }^{11}$. Y recientemente todavía ha agregado alguna información más Javier Hernández ${ }^{12}$. Las contribuciones de esos tres autores amplían el conocimiento de los hechos desde el punto de vista de la monarquía. Faltaba, en todo caso, considerar y documentar el asunto desde la perspectiva Borja ${ }^{13}$; y también desde la de Roma, jurisdiccionalmente el árbitro del contencioso.

No se trata en consecuencia de descubrir el suceso, sino de procurar conocerlo mejor e intentar comprenderlo con todas sus implicaciones, trastiendas - actores y circunstancias - incluidas. La compilación de una relativamente copiosa base documental - más de una treintena de textos-, en parte publicada pero de manera harto dispersa y que ha merecido por ello escasa atención, y la incorporación de algunas piezas fundamentales antes no consideradas, debe hacerlo posible; $y$, de paso, debe ayudar a iluminar también la disputa de fondo.

$$
* * *
$$

Ya el día antes de la elección estaba el virrey perfectamente al cabo del cisma que se avecinaba, e informó de ello al príncipe regente Felipe. Su pa-

8 SAMPER, 1669, vol. II: 550; la noticia que sigue, en el mismo lugar, II: 425.

9 HAMPE MARTÍNEZ, 1990: 68-69; antes, HAMPE MARTINEZ, 13 (Valencia, 1987): 75-98; 92.

10 Por ejemplo, SAMPER, 1669, II: 548; ANDRÉS ROBRES, 2014a: 295-296.

${ }^{11}$ MARTÍ FERRANDO, 2002: 98-102.

12 HERNÁNDEZ RUANO, 2014: 151-154. Es libro que procede de su tesis doctoral (HERNÁNDEZ RUANO, 2004), pero el tratamiento de ese episodio ha sido incorporado ahora: lo conoce desde Samper, Hampe y algunas reales cartas.

13 Apenas se tropezó con él en su biografía sobre el santo GARCÍA HERNÁN, 1999: 117-118. 
dre, Carlos, había partido de España en 1543 — no regresaría hasta 1557ocupado en las disputas con Francia por los territorios italianos y, en Alemania, con los príncipes protestantes: se encontraba entonces en los Países Bajos. Escribió el duque de Calabria ${ }^{14}$ :

Después que murió el maestre de Montesa están juntos en aquel convento todos los comendadores y freyles de aquella orden sobre la elección de nuevo maestre. Y según las passiones y zizañas que entre ellos concurren, se crehe y se tiene por çierto que no podrán concordarse, antes elegirán dos, y que havrá entre ellos pleyto y grande discordia. Y con esta sisma serán forçados de recorrer a Su Magestad y a Roma, de que avisaré a vuestra merced con correo aposta en declarándose la dicha elecçión, que será presto. Y si necessario fuere, porné [pondré] secresto en el Maestrazgo y me informaré si es verdad lo que públicamente se dize, que se han vendido los votos y que han concurrido millares de ducados sobrello, para que conforme aquello se provea en todo lo que más al serviçio de su Magestad cumpla ${ }^{15}$.

Consideró el virrey, en efecto, que era necesario y habría pasado a los hechos, encomendando el gobierno de la orden al comendador mayor Pedro Luis Galcerán- (y, en su minoría, al caballero que venía ejerciendo como tal, frey Gerónimo Pardo de la Casta), pero la administración económica a alguien ajeno a Montesa, don Ximén Pérez Pertusa, como relata el cronista $^{16}$. Sendas y recíprocas cartas del príncipe Felipe y Carlos V de mayo y julio de 1544 refieren y constatan el secuestro ${ }^{17}$, que es posible verificar tam-

14 El virrey de Valencia duque de Calabria, don Fernando de Aragón; para contextualizarlo, MARTÍ FERRANDO, 26 (Valencia, 2000): 95-112; es resumen de su tesis doctoral, que lleva el mismo título.

15 Cit. por MARTÍ FERRANDO, 2002: 99 (de AGS, Estado - Aragón, 293, f. 91, Valencia, 4 de abril de 1544). Recoge Martí bastante de lo ocurrido en los primeros meses.

16 «Llegó esto a tanto extremo que el Virrey y Capitán General de el Reyno hubo de mandar sossegar a las partes, y que la Real Audiencia determisasse de justicia lo que [se] devía hazer. Assí se hizo, y la Real Audiencia resolvió que el gobierno de la orden pertenecía al comendador mayor, y por su menor edad a quien regía la dignidad, que era Fr. Don Gerónymo Pardo de la Casta; pero para la administración y cobrança de las rentas y pecunias de la Orden nombró a D. Ximén Pérez Pertusa, por cuya mano corrió esta materia hasta que hubo Maestre». SAMPER, 1669: II, 549. Don Ximèn Pérez de Pertusa aparece en crónicas y tratados clásicos (Viciana, Escolano, Andrés de Uztarroz, Madramany y Calatayud...) como generòs, jurat en cap de los caballeros de Valencia o incluso como gobernador, pero nunca como caballero de Montesa; sí pudo llegar a serlo algún descendiente con el mismo nombre (véase CERDÀ I BALLESTER, 2014: 475), pero tampoco es seguro, menos considerando que frey Hipólito no establece la posible relación. Véase también la nota 18.

17 En concreto, fechadas en 14 de mayo - la de Felipe - y 6 julio — la de Carlos-. Se describen y documentan con detalle después, en las notas 24 y 31 . Leemos en la primera: «El duque don Hernando [virrey duque de Calabria...] scriue que tomará la possessión de las tierras y rentas que tocan al Maestre entre tanto que se vee por justicia a quién pertenesce». Carlos daba el secuestro por hecho: «lo que el duque don Hernando en caso de discordia, por 
bién en documentación de la Orden ${ }^{18}$.

De la misma cita resulta también destacable la nada velada alusión a los dineros que, al parecer, Francisco de Borja habría repartido para comprar voluntades en favor de su medio hermano Galcerán. Los sobornos también pudieron haber mediado en anteriores episodios del cerco de los Borja a Montesa, de la mano entonces del padre de ambos, el duque don Juan ${ }^{19}$. Ni entonces ni ahora las denuncias traerían consecuencias.

El príncipe se dio apenas por enterado, aprobando la gestión del virrey a vuelta de correo, el 8 de abril ${ }^{20}$. Ese mismo día escribió - tres en una- a Francisco de Borja, a la duquesa viuda y a Galcerán ${ }^{21}$, que le habían informado por su cuenta. Amable, como no podía ser de otra manera: «he holgado de la electión de don Pedro, y la voluntad que tengo de fauorescelle en ello y en todo lo que le tocare, y no será la menor causa dessearlo vos» (a la duquesa viuda - que, por cierto, le estaba pidiendo al tiempo la gobernación de Xàtiva para Felipe Manuel, otro de sus hijos). Pero cauto: «me ha desplazido de que aya la diuisión que scrivís» (a Francisco); «holgara mucho más que fuera sin la competencia que dezís que en ella ha hauido» (a Galcerán). Y, en su papel de regente, esperando a la opinión al respecto del César: «scrivo al emperador, mi señor, muy encaresçidamente para que le fauorezca con Su Santidad, y assý tengo por cierto que lo hará» (a Francisco); «y con el primero [correo] tengo por cierto $\mathrm{S}$. M. ${ }^{\mathrm{t}}$ me avisará de su voluntad» (a la duquesa).

Que sepamos, tardó sin embargo más de un mes en informar a su padre. Recibió antes una carta de la esposa de Francisco, Leonor de Castro, la duquesa en ejercicio, que comprendemos mejor si recordamos los estrechos vínculos entre los Borja y los Habsburgo fruto de la política matrimonial con Portugal: Leonor había sido camarera de la difunta emperatriz Isabel (†1539), esposa de Carlos; de estos había partido la idea, hasta lograrlo, de casarla con

evitar differencias y scándalos estre los eligidos proveyó de tomar la possessión de las tierras y rentas del Maestradgo, hasta que se declare por justicia, ha parescido muy bien».

18 Por ejemplo en una anotación de 20 de marzo de 1545 por la que consta un pago de cuarenta libras hecho por el citado Ximèn Pérez, «caballero administrador del Maestrazgo de Montesa nombrado por la Real Audiencia», en favor del subcomendador del convento, frey Gerónymo Roca, a cuenta de sus alimentos: AHN, OOMM, libro 816C, «Catálogos y memorias de las personas de hábito en la Orden de Montesa [...]. Del Archivo General de la Orden de Montesa, Armario XVII, Estante 1». Agradezco la noticia a Josep Cerdà i Ballester, quien también me ha confiado no haber hallado rastro de la posible relación entre los dos Pérez Pertusa, entre otras indicaciones para mejorar el texto.

19 ANDRÉS ROBRES, 2014a: 284.

20 «La diligencia que habéis hecho en la electión del Maestre de Montesa para que se haga canónicamente y como conviene, ha sido muy buena. Avisadnos como scrivís que lo haréis» (de AGS, Estado - Aragón, leg. 291, f. 154, Valladolid, 8 de abril de 1544): cit. por MARTÍ FERRANDO, 2002: 102.

21 Monumenta Borgia II: 683-684. Desde Valladolid [AGS, Estado, leg. 291]. 
el entonces heredero de Gandía, contra los deseos iniciales del III duque don Juan de Borja ${ }^{22}$; en la misiva, llena de lugares comunes, la duquesa apoyaba por supuesto y con firmeza a su «hermano» Galcerán ${ }^{23}$. Sin embargo, cuando Felipe escribió al fin a Carlos (14 de mayo), tras resumir el enconado resultado de la elección y la actuación del virrey para controlar la situación, se mostraba abiertamente partidario de intentar la incorporación:

Bien se acordará V. Md. de lo que se ha hablado otras veces sobre este Maestrazgo, y lo que se scrivió a Su Santidad para que tuviesse por bien de incorporarlo en la Corona real, como lo están los de Castilla, por los grandes y evidentes beneficios que dello se siguen. Y como entonçes no se despachó, agora, con esta ocasión desta scisura y división que hay entre los dos elegidos, paresce que habría buena coyuntura para tornar a supplicarlo a Su Santidad, y que V. Md. debría scrivir a Juan de Vega [entonces embajador en Roma] para que con todo calor y instancia lo procurasse. Vuestra Magestad verá lo que en ello será más servido, pues conosçe mejor que nadie lo que importa ${ }^{24}$.

A destacar la referencia a la relativamente reciente y definitiva incorporación de los maestrazgos de las órdenes castellanas (bula Dum intra, Adriano VI, $1523^{25}$ ) y a los intentos anteriores respecto de la propia Montesa. Y el reconocimiento de la autoridad última del Emperador. Felipe era por otra parte consciente de las posibles dificultades; y, de resultar insalvables, contemplaba la opción Borja, que en su opinión apoyaban «los más ancianos y más

22 Para esos asuntos, con prolijidad, GARCÍA HERNÁN, 1999: 45-60. Solo un detalle que añadir: también Pedro Luis Galcerán de Borja casaría con una dama portuguesa, y con el mismo nombre de pila: doña Leonor Manuel. Sería en 1558, a instancias de Francisco y no sin dificultades, que este sorteó: fue don Pedro el primer caballero montesiano que contrajo matrimonio, acogido a la llamada «bula del casar» concedida pocos años atrás (1540) por Paulo III a los caballeros calatravos y bien conocida.

23 «Aunque el Duque [Francisco] escribe a V. Alteza suplicándole mande mirar que en la justicia que pretende tener D. Pedro [Luis Galcerán] de Borja, mi hermano, en la elección que han hecho a su persona de Maestre de Montesa, no le sea hecho agravio ninguno, no quiero yo dejar de suplicar a V. Alteza nos haga a todos esta merced; pues como acostumbramos a recibillas de sus reales manos, pienso será servido de mandárnosla hacer en esto. Pues el bien que en esta casa se desea no es sino para emplealle en el servicio de V. Alteza, como hechura de sus manos»: Monumenta Borgia I: 585-586. Gandía, 18 de abril de 1544.

24 Valladolid, 14 de mayo de 1544. AGS Estado, leg. 69, f. 101: CORPUS DEL EMPERADOR CARLOS V..., II: 220-224; la reproducen en parte MARTÍ FERRANDO, 2002: 100, y HERNÁNDEZ RUANO, 2014: 152-153. De allí proceden también el entrecomillado del párrafo siguiente y la nota al pie asociada.

25 Describe el proceso de incorporación de las órdenes castellanas POSTIGO CASTELLANOS, 1988: 39-44. Más detalles del de Calatrava, de la que Montesa era - como es sabido- filiación, en FERNÁNDEZ IZQUIERDO, 1992: 48-56. El texto completo de la bula puede consultarse, en versiones latina y castellana, en HERMOSA DE SANTIAGO, 1880: 242-252. 
qualificados» caballeros de Montesa. Pesaban, seguro, las estrechas relaciones a que antes se ha hecho referencia, y no ocultaba a su padre haber recibido cartas desde Gandía «pidiendo que le ayudasse y favoreciesse en su electión [en la elección de Galcerán]» ${ }^{26}$.

El Emperador se tomó también su tiempo en responder. Siete semanas. Lo hizo en larguísima carta que abordaba múltiples asuntos — también la de su hijo: correo oficial ordinario, atendido por secretarios - Estaba de acuerdo, según interpreto, en todo. En favorecer a Galcerán «quando no se pudiera acabar», esto es, en caso de no lograrse la incorporación: considérese que Carlos bien podía sentirse por entonces doblemente deudor de Francisco de Borja, por su relevo como virrey de Cataluña en contra de su voluntad y, sobre todo, por el recientísimo fiasco tras proponerlo, junto con su esposa, como mayordomo mayor - y camarera mayor - de los príncipes Felipe y María Manuela - casaron en 1543 - , habiendo sido rotundamente rechazados para ocupar los cargos por los reyes de Portugal ${ }^{27}$ : el padre e historiador jesuita Pierre Suau lo afirmaba expresamente en supuestas palabras del propio Emperador ${ }^{28}$; podía colear, por último, el recuerdo de las no tan lejanas Germanías, en que la ayuda del III duque de Borja habría sido importante para sofocar el movimiento, que - por cierto- adquirió especial relevancia en el territorio de Montesa $^{29}$. Pero lo más importante es, sin duda, que Carlos V se mos-

26 «Y en caso que esto [la incorporación] no paresciesse a V. Md. hazedero, o que no convenga ni devía pedirse en esta coyuntura, no puedo dexar de recordar a V. Md. lo mucho que el duque y la duquesa de Gandía merescen y la razón que hay para que ellos y sus cosas sean favorescidas, y supplicar a V. Md. que tenga por muy encomendado a don Pedro [Luis Galcerán] de Borja y le haga todo favor y merced, que cierto, de más de que aquella Orden recibe mucho beneficio, en él será bien empleada».

27 GARCÍA HERNÁN, 1999: 105-110 y 112-116 respectivamente. El relevo de Cataluña, en plena guerra con Francia, que asediaba el Rosellón, pudo tener que ver con el envío a la zona del duque de Alba, para evitar conflictos entre ambos. En cuanto al rechazo de Juan III (y de su esposa Catalina de Austria, hija de Juana [la Loca], con quien Francisco había intimado desde niño en Tordesillas), se tiende a explicar por el mal carácter de Leonor de Castro, sospechosa además en Portugal de intrigar contra los intereses de aquella monarquía en favor de la española. Ofrece muchos detalles al respecto, con referencia además a acreditados autores borgianos (Batllori, Josep María Benítez Riera), LA PARRA LÓPEZ, 2011: 148-149. De conseguir el puesto, Francisco bien podría haberse convertido en el principal consejero del futuro Felipe II.

28 «Considerando que Nos ordenamos al duque aceptar este oficio, y que Nos lo retiramos, a este efecto, de su cargo de virrey, Nos cuidaremos de darle una mejor encomienda y de favorecerlo como él merece» (sin referencia archivística en SUAU, 1963: 129-143; el mejoramiento de encomienda está documentado: Huélamo (Cuenca) por Reina (Badajoz). DALMASES, 2002: 60.

29 Sobre la intervención del duque, que apoyó y financió la causa real, debió huir de sus dominios cuando la guerra y resultó herido - en la cara - en batalla, PONS FUSTER, 2008, que recoge lo esencial de la cronística clásica: especialmente, 141-145; 188-191; 197-198; 
tró de acuerdo en intentar la incorporación, «lo qual, si se pudiesse hazer, sería muy bueno». Era sabedor de que se trataba de un objetivo casi imposible, dadas sus para entonces pésimas relaciones con Pablo III: «el tiempo no es muy oportuno ni el stado en que están las cosas con el Papa para procurar esta reunión» ${ }^{30}$. Pero pese a todo iba a intentarlo: «havemos mandado screvir que se procure con esta ocasión de la división, haziendo todas las diligencias que podrán aprovechar por todos los medios que se vieren convenir para acabarlo, si ser pudiere» ${ }^{31}$. Lo hizo, de hecho, casi de inmediato.

La mejor prueba de que así fue la constituye un precioso documento que debemos a Pedro de Marquina, secretario del entonces embajador de Carlos V en Roma don Juan de Vega y al que suplía en aquellos meses ${ }^{32}$. No es texto del todo desconocido, pero las insuficientes transcripción y descripción que de él se han hecho con anterioridad ${ }^{33}$ han aconsejado revisar el original manuscrito ${ }^{34}$. Montesa es un punto más en una larga carta-informe al emperador en el que Marquina resume una también larga entrevista con el Pontífice: «Ayer, que fueron XXII [de julio de 1544], estuve con Su Santidad bien dos oras...». Se pasa en él revista a todas las cuestiones entonces candentes entre Carlos y Paulo III. Está salpicado de desconfianza: siempre a la defensiva el Papa, receloso ante cualquier propuesta, ya fuera el nombramiento de un obispo ya la solicitud expresa de ayuda para la guerra contra Francisco I «contra el turco»- Pero tampoco se trató de un punto marginal: mereció, por el contrario, unos buenos párrafos. Dice Marquina haber aprovechado para plantearlo un momento que consideró idóneo, pues «hablava [el pontífi-

215-216; para el movimiento en el Maestrazgo, VALLÉS BORRÁS, 2000: 105-111; existe sobre el particular una interesante crónica que publicó el mismo autor: VALLÉS BORRÁS, 1990: 59-70.

30 Resumo: cuarta guerra con Francia, esta vez en alianza con Inglaterra y apoyada en la paz alemana — paz con los electores luteranos, que le ayudaron—, que derivó de la dieta de Espira de febrero de $1544 \ldots$ que había irritado al Papa; quien, por otra parte, desesperaba al Emperador en su tibieza —o política de neutralidad-, respecto de su enfrentamiento con el rey francés a pesar de la alianza de este con el turco; y más que tensas vísperas de Trento.

31 Las citas del párrafo, en la carta del Emperador al príncipe Felipe, desde Metz, a 6 de Julio de 1544. AGS, Estado, leg. 500, ff. 51-57: CORPUS DEL EMPERADOR CARLOS V..., II: 249-251. MARTÍ FERRANDO, 2002: 100, que también la conoce (como HERNÁNDEZ RUANO, 2014: 152-153), hace una interpretación distinta de ese documento.

32 Marquina, clérigo, tal vez jesuita desde 1547, fue amigo de Ignacio de Loyola. Contribuiría después, a su regreso a España, a la financiación del colegio de la Compañía en la ciudad de Cuenca, de cuya catedral fue canónigo. Informa de su pensamiento y relación con el fundador GARCÍA HERNÁN, 2013: 162.

33 SALTILLO, 1946: 102-103.

34 BNE, ms. 18417 (microfilm 14148), Cartas de Juan de Vega al Emperador, 15431547: fols. 254-262, Roma, 26 de julio de 1544. Desde donde bebe lo que sigue hasta nuevo aviso. 
ce] en [sobre] Vuestra Magestad sin el rencor que alguna vez he visto» ${ }^{35}$, para decirle

que también me mandaba Vuestra Magestad, por obviar a las discordias y otras passiones que quedan en el Reyno de Valencia de cada electión que se haze de maestro de Montesa, de que venía gran escándalo en los cavalleros que ay en él por las competençias que tienen, suplicasse a Su Santidad en nombre de Vuestra Magestad por la encorporación del dicho maestradgo, y ansí se lo suplicaba por ella humilmente (sic), çertificándole que tenía por çierto que dello se sirviría Nuestro Señor mucho, dejado aparte que las electiones se harían por Vuestra Magestad más conformes a lo bueno, y advertiéndole que este maestradgo no creýa que podía ser si no de poca quantidad ni abía de venir en consideraçión con los que ay en Castilla.

Pero según parece, la decisión del papa Farnesio de continuar con los regalos a los Borja - recordamos que habían precedido dos capelos- estaba tomada; por otra parte, se le habría inoculado cierta especie en clave constitucional, seguro no sin intención:

Detúvose un poco [el papa] y respondió: que dos cosas le ocurrían al presente; una que estaba informado que las leyes de los Reynos de Aragón, Valençia y Catalunya le dezían que difirían de las de Castilla; y otra que por la voluntad que tiene a la casa de Borja había confirmado la electión que se había hecho en un hermano del duque de Gandía.

Para no dar el asunto por completamente perdido, Marquina — dice- respondió que se documentaría él mismo y le trasladaría más información respecto de «la qualidad del maestradgo», probablemente con la intención estratégica de continuar minimizando el alcance de lo que estaba en juego, ya claramente manifestada en el texto. Después, como excelente diplomático — si hemos de creerle ${ }^{36}$ - calló: lo narra, desde luego, con suma elegancia:

[...] y como Vuestra Magestad me mandaba que, [si] hechas mis diligencias a fin de aver la graçia no me quedasse esperança della, favoresçiesse la justicia del hermano del duque [de Gandía], viendo que Su Santidad, sin medio de Vuestra Ma-

35 Considérese que en el mismo documento se puede leer que en otro momento de la conversación, y sobre otro asunto, «saltó tan presto [el papa] en su respuesta con una cólera que la iva reprimiendo, dando cuenta de lo que avía pasado con Su Magestad sobre ella...», ibid.: fol. 260.

36 La impresión, tanto por lo visto como por lo que sigue, es que Marquina no habría - supuestamente - tratado de favorecer en el negocio a su amigo Francisco; antes, habría mantenido, obedeciendo las órdenes recibidas, la posición e intereses de la monarquía. Ahora bien: como el desenlace sí benefició a los Borja y nos movemos en el sutil terreno de las artes diplomáticas, y en Roma, todo es posible. 
gestad, avía confirmado su electión, dissimulé esta postrera particularidad por que lo que había hecho de su motivo no lo vendiesse a Vuestra Magestad.

Solo una cosa más sabemos: algo habría arrancado el Pontífice para un nepote: no había que perder las costumbres. Después de la cita que sigue, que tiene la misma procedencia - unos párrafos más adelante en el escrito, un día más tarde en el tiempo-, ninguna otra referencia a Montesa hay, que sepamos, ni en esa ni en ninguna otra carta de la colección:

Ayer que fueron XXIII [de julio de 1544] quise informarme del estado en que estaba lo del maestradgo de Montesa y supe que Su Sanctidad había reservado quinientos ducados de pinsión en él al Prior de Venecia, su nieto, y affirmáronme que los que negoçiaban por el duque de Gandía avían movido por sus respectos a Su Santidad esta reservación; pocas cosas ay desta qualidad, y peores, que aquí no intenten los naturales ${ }^{37}$.

Siguen cuatro meses sin noticias, pero en los que parece que no habría ocurrido nada relevante; salvo quizá, precisamente, la lentitud con que se produjeron las cosas: todo estaba detenido en Roma, en apariencia a causa de problemas burocráticos, aunque debieron de serlo también económicos; coleaba, así mismo, el intento de frey Guerau Bou por hacer valer sus derechos. El caso es que los papeles con la designación de Pedro Luis Galcerán de Borja y Castro-Pinós como maestre de Montesa no llegaban, o no lo hacían en las condiciones debidas. La consecuencia no fue otra que un aluvión de solicitudes desde Gandía a la Corona para que les ayudase a conseguirlos con prontitud. Escribieron así, en noviembre y diciembre de 1544, el duque Francisco, la duquesa viuda Francisca y el propio Galcerán. Se dirigieron en alguna ocasión al príncipe Felipe, pero en bastantes más a Francisco de los Cobos, el veterano y poderoso secretario de Carlos $\mathrm{V}$ que había quedado en España para auxiliar en las tareas de gobierno al joven regente. No es detalle sin importancia: la relación de Francisco de Borja con Cobos $-\mathrm{y}$ con su mujer, María- se remontaba a mucho tiempo atrás y fue siempre excelente ${ }^{38}$. Cobos actuó como maestro de ceremonias en la boda de Francisco con Leonor $(1529)^{39}$, fue también quien diez años después le impuso el hábito de Santiago en su condición de Comendador Mayor de León, la más alta dignidad de aquella orden ${ }^{40}$, e intentó hasta el último momento que los monarcas portu-

37 La pensión no ha dejado huella en la documentación económica de Montesa al alcance (véase, por todos, BREVE RESOLUCIÓN..., 2004: 81-84); que no es nunca, por otra parte, en lo referido a gastos, anterior a 1592. Por otra parte quienes fueron «los naturales» aludidos -romanos o valencianos - quede al arbitrio del lector.

38 KENISTON, 1980: 275-276.

39 GARCÍA HERNÁN, 1999: 55.

40 FERNÁNDEZ IZQUIERDO, 2011: 79-102; antes, LAURENCÍN, 22 (Madrid, 1893): $130-168$. 
gueses aceptaran a los duques de Gandía como mayordomo y camarera mayor de los príncipes Felipe y María Manuela, sin éxito como se ha dicho ya, cuestión por la que también pudiera sentirse en deuda con Francisco de Borja. Las cartas son diplomáticas, pero también exigentes ${ }^{41}$.

Utilizaron los Borja todavía más cartuchos y ardides. Como sugerir a Felipe que tocara también como intercesores a Margarita de Austria (1522-1586), la hija natural del emperador casada en 1539 con Octavio Farnesio — por ello, después, duquesa de Parma y gobernadora de los Países Bajos hasta la llegada del duque de Alba-, y a otro Alejandro Farnesio (1520-1589), nieto, como Octavio, del Pontífice... y cardenal. El ardid, la siempre lastimosa actitud de la duquesa viuda: «se sirva su Alteza escribir sobre lo mesmo a Madama, su hija del Emperador nuestro Señor, y al Reverendísimo Cardenal Fernés [...]; acabo, por no dar pesadumbre con más prolijidad, de suplicar a V. S. se acuerde de mi soledad y destos desdichados servidores de V. S.»» ${ }^{42}$.

41 Algunos ejemplos: «Muy Ill. ${ }^{\text {e }}$ Señor. Con la tardança del correo ordinario de Roma se ha tardado el despacho de la merced que Su Sanctidad ha hecho del maestrado de Montesa al señor don Pedro [Luis Galcerán] mi hermano, y con haver llegado agora [...] no han embiado el breve original en forma [...], a causa que, por no saberse la cantidad, no se ha podido hazer la provisión del dinero; y assí la manda hazer agora mi señora la duquesa [Francisca], para que con todo cumplimiento se despache; y assí para entender en esto, como para dar orden en que se despache el impedimento que pone el comendador Bou [...], embía mi señora la duquesa una persona a Roma, y hame pedido que suplique a V. S. nos haga merced a todos de supplicar a S. A. [el príncipe Felipe] sea servido de scrivir a Su Sanctidad en recomendación destos negocios» (Francisco de Borja a Francisco de los Cobos. Gandía, 26/11/1544: Monumenta Borgia II: 491-492. AGS, Estado, leg. 293); «como me escriben de Roma que provea del dinero para la expedición de las Bulas [...] soy forzada de enviar una persona en Roma para abreviar la expedición del negocio; y como ningún medio pueda ser tanta parte para esto como el favor del Príncipe nuestro Señor y la intercesión de V. S., cuanto puedo le suplico [...] interceda con su Alteza sea servido de favorecer a mi hijo, escribiendo a su Santidad en recomendación del efecto de esta merced» (Francisca de Castro-Pinós, duquesa viuda, a Francisco de los Cobos. Gandía, 8/12/1544: Monumenta Borgia I: 435-436); «aunque sea atrevimiento importunar a V. Alteza sobre una cosa tantas veces, la merced que nuestro muy Santo Padre me ha hecho en confirmar mi elección, me fuerza a suplicar a V. Alteza sea servido escribir a su Sanctidad en mi recomendación sobre el efecto de esta merced...» (Pedro Luis Galcerán de Borja al príncipe Felipe. Gandía, 9/11/1544: Monumenta Borgia I: 436-437). El mismo día hay otra con el mismo contenido, dirigida por el mismo remitente a Francisco de los Cobos: Monumenta Borgia VI: 632-633. AGS, Estado, leg. 293, f. 253, original.

42 Francisca de Castro-Pinós a Francisco de los Cobos. Gandía, 8/12/1544: Monumenta Borgia I: 435-436. La intercesión ante Margarita había sido solicitada previamente en carta de Francisco de Borja al mismo Francisco de los Cobos (Gandía, 28/11/1544: Monumenta Borgia II: 492-493. AGS, Estado, leg. 293) que refleja, por otra parte, lo alambicado de las solicitudes en lo que se refiere a la arquitectura relacional: «mi señora la duquesa [Leonor] ha embiado a pedir a la duquesa [viuda: Francisca] que suplicasse también a V. S. [Cobos] nos hiziesse merced a todos de suplicar a S. A. [el Príncipe Felipe] por otra carta para madama [Margarita de Austria], sobre los mesmos negocios de Montesa que se ha de escrivir a Su Sanctidad [Paulo III]». 
En todo caso, el acceso de Galcerán al maestrazgo de Montesa se daba por poco menos que hecho, solo a falta del mencionado trámite. Ya no solo desde la casa ducal de Gandía, sino por el propio Emperador, que en enero de 1555 lo reconocía expresamente en carta a su hijo desde Gante; eso sí, proponiéndose tomar posiciones de cara a la siguiente elección:

\begin{abstract}
Ya que lo del maestrado de Montesa no se pudo hacer en esta electión, se escribirá a Joan de Vega que mire de tractallo, y asegurarlo para adelante por los medios que mejor viere convenir; y cierto sería muy grand bien que esta dignidad se incorporasse en la Corona Real ${ }^{43}$.
\end{abstract}

El asunto todavía iba a reverdecer, sin embargo, con la aparición en escena del entonces licenciado y clérigo Pedro de la Gasca, quien llegaría a ser después célebre como presidente de la Real Audiencia de Lima, gobernador del Perú (1546-1550) y exitoso responsable de sofocar la rebelión de Gonzalo Pizarro y de poner orden en el virreinato, de resultas de lo cual recibiría a su regreso a España los obispados de Palencia (1551) y Sigüenza (1562). Pero que a comienzos de 1545 ejercía como visitador real — juez de residencia - del Reino de Valencia, designado por Carlos V en las Cortes de Monzón (1542). Y que fue autor, se adelantó ya, del documento por el que el episodio que intentamos reconstruir fue dado a conocer en primera instancia - excluido Samper- por Teodoro Hampe ${ }^{44}$.

Ese texto, fechado en Valencia a 20 de enero de 1545 y que lleva anexa una «memoria» del señorío del maestrazgo de Montesa con rica información sobre su población y renta en la época, es, formalmente, una breve cartainforme del visitador a Francisco de los $\operatorname{Cobos}^{45}$; aunque con la intención evidente de que se elevara no ya al príncipe Felipe, sino al Emperador: «para enviar a Flandes», se lee de hecho en el encabezamiento del sobre que antecede al original en el legajo. Y tiene sin duda gran interés. Recientemente ha sido transcrito íntegro, publicado y comentado ${ }^{46}$. Ello exonera de tener que

43 Carlos V a Felipe II. Gante, 13 de enero de 1545; AGS, Estado, leg. 501, ff. 10-11: CORPUS DEL EMPERADOR CARLOS V..., II: 323; menciona también la carta HERNÁNDEZ RUANO, 2014: 153 ( $c f r$.). Esa esperada próxima ocasión (así hay que entender, pienso, el «para adelante») no se habría de presentar hasta casi cincuenta años después, dada la longevidad de Pedro Luis Galcerán.

44 Remito a las obras citadas en la nota 9; Hampe lo conoció exclusivamente desde esa pieza y desde la carta del Emperador al príncipe Felipe de mayo de 1545 que se cita en la nota 53.

45 Puede ser consultado en AGS, Estado Aragón, 297, ff. 307-308.

46 ANDRÉS ROBRES, 2014b: 474-478. Lo incluyó Hampe, al parecer, en el apéndice documental de su tesis doctoral (HAMPE MARTÍNEZ, 1986), pero no en las publicaciones que de ella derivaron; lo conoció también MARTÍ FERRANDO, 2002, que lo nombra y utiliza: 100-101; y lo cita asimismo HERNÁNDEZ RUANO, 2014: 153, a partir de Hampe. 
hacerlo aquí en extenso, por lo que me limito a recordar lo principal de su contenido.

En él Pedro de la Gasca propugna la incorporación a la Corona del maestrazgo de Montesa. Fervientemente. Lo irregular de la elección maestral de 1544 , en que los dos candidatos han jugado sucio prometiendo a los electores recompensas a cambio del voto, la invalida, deslegitimando de paso a ambos. Glosa a continuación el visitador las muchas ventajas que de ello derivarían. Las económicas no serían las más relevantes, con resultar el señorío goloso - era, hay que recordarlo, el principal del Reino ${ }^{47}$ — y estar poblado de muchos y buenos — por mayoritariamente cristiano-viejos - vasallos, que verían además el cambio con tan buenos ojos que estarían incluso dispuestos a satisfacer un importante donativo caso de llevarse a cabo. Más valor tendría desde un punto de vista político, dada la presencia de la Orden en Cortes y en otros órganos de representación del Reino en el brazo eclesiástico. Pero la importancia mayor residiría en la posibilidad de disponer la Corona de mercedes (hábitos, encomiendas, cargos diversos) con las que poder contentar -y amansar, añadimos-, a la nobleza del reino haciéndola «cortesana», esto es, quitándola del comportamiento violento y escasamente afecto a la monarquía que hasta entonces habría exhibido ${ }^{48}$. Propone al fin, para concretar el intento, y tras sugerir que de inmediato se intentase conseguir de Roma facultad para administrar en todo la orden hasta que la anexión se consumase, dos posibles alternativas: bien la incorporación directa con el virrey como administrador directo, bien promocionar como nuevo maestre al propio virrey, el ya para entonces añoso duque de Calabria, de 56 años, quien naturalmente consentiría, después de haberle sido otorgada tan gran merced, consumar la incorporación, que podría verificarse tranquilamente después de sus días.

El documento sorprende, sin embargo... en su cronología. Pensaba Pedro de la Gasca que el conflicto continuaba vivo y abierto, sin resolver, a la altura

Agradezco a Rafael Benítez Sánchez-Blanco su ayuda en la resolución de los problemas paleográficos y de interpretación que presenta.

47 ARDIT LUCAS, 2012: 41-60.

48 ... y exhibiría. El escrito de Pedro de la Gasca resulta en este punto doblemente premonitorio. Primero, la nobleza valenciana iba a continuar haciendo gala de su carácter levantisco en el futuro inmediato al no sustanciarse la incorporación: de hecho, a punto estaba de producirse uno de los más violentos estallidos de cuantos conocemos, en el que precisamente los Borja, y en concreto don Pedro Luis Galcerán - ya maestre-, se vieron gravemente involucrados; la bibliografía al respecto es extensa, pero me limito aquí a reseñar una contribución reciente que da cuenta de la situación en esa coyuntura e incorpora noticias de otras anteriores: URZAINQUI, 2007. Segundo, Montesa se convertiría de hecho en importante almacén de distribución de mercedes $-\mathrm{y}$, lo que es lo mismo, en herramienta para el apaciguamiento de la nobleza regnícola - en manos de la Corona en cuanto tuvo lugar la incorporación, como acaba de poner de manifiesto el amplio y minucioso estudio sobre sus caballeros (y religiosos) de CERDÀ I BALLESTER, 2014. 
de fines de enero de 1545, esto es, más de diez meses después de que estallara: que se encontraba, sencillamente, en suspenso - y en curso-, en Roma ${ }^{49}$. $\mathrm{Y}$ hemos podido comprobar aquí que eso no era cierto. La carta de Carlos V a su hijo de apenas una semana antes del escrito del visitador y que se acaba de citar lo atestigua. Y sobre todo sabemos por Pedro de Marquina que la decisión habría sido tomada ya por el papa Farnesio cuando menos seis meses antes, en julio de 1544. Formalmente, tal vez, el pleito podía seguir en curso. Los papeles con la sanción favorable al candidato Borja no habían llegado, en efecto, todavía, o no - al menos-, con las formalidades requeridas, y la intranquilidad de la duquesa viuda de Gandía y madre de Pedro Luis Galcerán de Borja es comprensible ${ }^{50}$. Todavía más: sabemos que frey Guerau Bou seguía meses después pretendiendo esgrimir sus derechos, entre sospechas — si no acusaciones-, de irregularidades, y denunciaba de manera muy gráfica a Francisco de los Cobos su indefensión en el «pleito» y las maquinaciones de los Borja en la Curia de Roma, reivindicando su condición de candidato que había obtenido mayor número de votos y pidiéndole ayuda para su causa ${ }^{51}$.

49 Reproduzco este único fragmento, dispuesto al comienzo del texto y desde el que el visitador justifica inmiscuirse en el asunto: «escriven de Roma que el pleyto sobre esta dignidad se tractava muy de rezio entre los dos que en discordia fueron a ella elegidos, y que Su Santidad havíe dicho que se conçertassen».

50 «[...] me escriben de Roma que provea del dinero para la expedición de las Bulas que, según mis trabajos, si se difiriese el efecto, sería intolerable el daño»: Francisca de CastroPinós a Cobos, Gandía, 8 de diciembre de 1544, Monumenta Borgia I: 435-436.

$51 \ll[\ldots]$ por tantas palabras y novedades que las gentes inventan sobre el pleito que entre el muy reverendo y egregio D. Pedro [Luis Galcerán] de Borgia, hijo del Duque de Gandía, que sea en gloria, de una, y mí de la otra parte, se trata in Curia Romana sobre las elecciones para Maestre de Montesa de nosotros hechas, porque dicen que Su Santidad, por vía Camare Apostolice, havría concedido un Breve apostólico al dicho D. Pedro, y por la dicha Cámara tome posesión del Maestrazgo y de los frutos, salvando mi derecho en el petitorio; y aunque esto paresce a muchos, como lo sería si así es, cosa nueva nunca acostumbrada, no dejan de sospechar que en Roma se inventan muchos trajes por hacer valer los oficiales sus oficios. Y aunque a mí, sospecha de hacérseme sin justicia no me ha movido ni me puede mover, especialmente en esa Corte de su Majestad donde Vuestra Señoría y otros señores y caballeros la hacéis por solo respecto de Dios y de vuestras honrras, pero la gente me embrega de tal arte que dicen [que] si para quando D. Pedro pida executoriales de su [elección] no hay alguna persona que proclame y defienda mi justicia tan justa, podrá ser que, por no haber parte que contradiga, se olvide mi justicia. Y aunque tengo por buena y suficiente parte ser interese [sic] y patrimonio de nuestra Señora el que se trata, y mi tan abundante justicia de ser elegido por la mayor parte, y ser cano y el otro mozo y, lo que más me confía, ser caballeros los jueces, por lo dicho me es forzado para informar, suplicar y acordar a V. ${ }^{a}$ S. ${ }^{a}$ todas estas cosas»: carta de frey Guerau Bou a Francisco de los Cobos, en Valencia a 22 de abril de 1545: Monumenta Borgia I: 437-438. Sorprende algo la reaparición del personaje ahora cuando, bastante tiempo atrás, Francisco de Borja apuntó, respecto de «el impedimento que pone el comendador Bou, que, según me dizen, se acabará [de solucionar] en breves días»: Francisco de Borja a Cobos, Gandía, 26 de noviembre de 1544, Monumenta Borgia II: 491-492. AGS, Estado, leg. 293. 
Con todo, ¿podía pensarse a estas alturas en una resolución desde Roma contraria a la determinación, tan claramente manifestada ya, del Pontífice? No parece probable. Y sin embargo el amago incorporador iba, como se dijo, a reverdecer. Aunque solo tímidamente según pienso. Y a ritmo, como casi siempre, lento. De la mano del príncipe Felipe, que a pesar de ser consciente de la situación, remitió a su padre el papel del visitador el 3 de abril de 1545 por si se animaba a hacer un último intento:

El licenciado Gasca ha visto las diferencias y contienda que ay sobre el Maestrazgo de Montesa, scrive la carta que yrá con esta sobre la incorporación en la corona real. $\mathrm{Y}$ aunque yo he scripto a Vuestra Magestad otra vez sobre esto [referencia, supongo, a la de Valladolid de 14 de mayo de 1544], todavía me ha parescido embiarla porque Vuestra Magestad la pueda mandar ver, y hazer en ella la provisión que más viere convenir; que si ello se pudiesse alcançar sería cosa de muy grand momento $^{52}$.

La respuesta del Emperador, desde Maastricht, se demoró ahora solo un mes, plazo normal. Resulta lacónica:

La que el Licenciado Lagasca os escribió sobre la incorporación del Maestrazgo de Montesa en nuestra Corona habemos visto, y si esto se pudiesse acabar no dexamos de conoscer que sería de muy gran momento y se terná cuidado de mirar, según los términos de las otras cosas, lo que se podrá hacer, siguiendo lo que ya otras veces se ha escrito sobre lo mismo ${ }^{53}$.

Pero la frase final, referencia a su anterior correo sobre el tema (la misiva ya también vista de Gante y 13 de enero de 1545) no deja, en mi opinión, lugar a dudas. Se verá lo que se podrá hacer... para intentar incorporar en una futura ocasión.

Por si alguna quedara, esa carta del Emperador se cruzó exactamente en fecha (5 de mayo de 1545) con la que Cobos le escribía para notificarle que se había dado un paso más en la irreversibilidad del proceso que favorecería al pretendiente Borja. Lo hacía en estos términos:

52 AGS, Estado-Aragón, leg. 297, ff. 313, apuntada por MARTÍ FERRANDO, 2002: 101, de donde tomamos la fecha de 3 de abril. Fue publicada en CORPUS DEL EMPERADOR CARLOS V..., II: 369-372: príncipe Felipe (Mejorada del Campo) a Carlos V, con fecha dudosa: ¿fines de marzo de 1545 ?.

53 Carlos V al príncipe Felipe, Maastricht, 5 de mayo de 1545. AGS Estado, leg. 501, ff. 46-68; se reproduce en CORPUS DEL EMPERADOR CARLOS V..., II: 380; la citan tanto MARTÍ FERRANDO, 2002: 101, como HAMPE MARTÍNEZ, 1990: 69; HERNÁNDEZ RUANO, 2014: 153-154 conoce también la carta, como seguramente la que se alude en la nota siguiente. 
[...] ha venido aquí un criado del duque de Gandia con las Bullas que Su Sanctidad ha concedido a don Pedro [Luis Galcerán] de Borja pidiendo que se le diessen los exequtoriales, y aunque sy se pudiera hazer lo que está scripto de la incorporaçión a la Corona fuera lo mejor, todavía haviéndose presentado las Bullas y hecha la declaraçión por Su Sanctidad, paresçe a los del Consejo de Aragón que no se le podían negar, y assý se despacharon y se le dieron ${ }^{54}$.

Quedaba únicamente conseguir que las cosas se hicieran con la debida elegancia, guardando las formas, como el Papa había pretendido siempre según sugiere su deseo de que los litigantes «se conçertassen» que recoge el escrito del licenciado Gasca. Que se concertasen significaba, sin embargo, lograr la renuncia definitiva y voluntaria de frey Guerau Bou, que todavía tardaría unos meses. Pero llegaría, como se anunció ya. Llegó el 19 de septiembre, e «ipso iure quedó maestre Fr. D. Pedro Luys Garcerán de Borja» ${ }^{55}$. Aquel mismo día, con bula expedida en Perugia, Paulo III salvaguardaba el honor de frey Bou, creándolo maestre «quando vacase la Dignidad por muerte, dexación o privación de Fr. D. Pedro Luys Garcerán de Borja. Pero esta merced más fue para el consuelo de el clavero que para que la gozasse; pues teniendo más de 60 años no era fácil sobreviviesse a los 17 del maestre». Desde luego que no lo conseguiría.

$$
* * *
$$

Teodoro Hampe, Josep Martí y Javier Hernández interpretan el episodio, con perspectiva en el largo plazo, en clave de incremento de la jurisdicción real. Y no les falta razón: el estrecho seguimiento que la monarquía hizo del proceso lo permite; es más: se intentó, de hecho, la incorporación. En sentido que podría considerarse complementario, Paulino Iradiel y José María Cruselles han escrito que, en la primera mitad del siglo XVI y en concreto tras la muerte de Alejandro VI (1503), se habría producido un cambio fundamental en la historia de la familia Borja, que desde su anterior autonomía habría llegado a la convicción de que «el único camino posible era el de la identificación con la empresa monárquica de Fernando II [de Aragón: el Católico] y luego la imperial de Carlos V»; mudanza en la que consideran capital el «au-

${ }^{54}$ Cobos a Carlos V, Valladolid a 5 de mayo de 1545. AGS, Estado, leg. 69, f. 41; minuta. En CORPUS DEL EMPERADOR CARLOS V..., II: 387-388.

55 SAMPER, 1669, II: 550. Tal vez tras haber recibido —al fin—, algún caudal de parte de la familia de su contrincante, aunque no podamos certificarlo. Sí sabemos, desde esa misma fuente y página, que el único hijo varón de Bou recibió más adelante otra posible recompensa... a pesar de su condición: «El clavero dexò un Hijo, no legítimo, que le llamaron don Luys Bou; y muerto su padre, el maestre Borja, con atención a lo mucho que le debía, le dio el hábito de caballero en el año 1559». También de allí procede lo que sigue hasta el final del párrafo. 
ge de la figura política de Francisco de Borja ${ }^{56}$. Santiago La Parra ha coincidido en la misma idea, con la que es ciertamente difícil no estar de acuerdo conociendo la evolución posterior, y añade el testimonio de que las siguientes generaciones reconocían la importancia central del IV duque y después santo en esa transformación ${ }^{57}$. Y recientemente ese mismo autor y José Martínez Millán nos han mostrado con todo lujo de detalles al Francisco de Borja cortesano, perfecto cumplidor de todas las exigencias del recien descrito por Baltasar de Castiglione, para concluir que «Borja perteneció a esa nobleza que ya no era feudal sino cortesana ${ }^{58}$.

Los hechos expuestos muestran - sin embargo-, que, a la altura de mediados del siglo $\mathrm{XVI}^{59}$, y a pesar del intento de incorporación, el asalto de los Borja a Montesa se había consumado, bajo la dirección primero del III duque, don Juan, y con la efectiva intervención final del IV, don Francisco de Borja y Aragón, que sin duda supo manejar los hilos en la más importante de las cortes - la Curia de Roma; también en la española-, en favor de su medio hermano Pedro Luis Galcerán. Los intereses de la poderosa familia habían prevalecido, al cabo, sobre los de la Corona. La coyuntura, seguramente en lo referido a la relación con el Papa, habría aconsejado a Carlos ceder. Y en tal caso la opción segunda - la alternativa - ya previa y conscientemente asumida tanto por el Emperador como por el Príncipe, era que el beneficiado por la cesión fuese el duque de Gandía, con quien se estaba en deuda y que resultaba ser también, evidentemente, el favorito de Paulo III. Se llega con ello a reparar en otra de las piezas del rompecabezas: la necesidad de la monarquía de continuar apoyándose en la nobleza, colaboradora necesaria en el mantenimiento de aquella formación social ${ }^{60}$. Como lo era también la Iglesia. Y las instancias intermedias que fueron las órdenes militares. Los poderes diversos, aliados, friccionaban no obstante: naturalmente. No se descubre nada nuevo, pero el argumento se ilustra — pensamos_-, con un ejemplo paradigmático a la vez que interesante dada la relevancia de los actores que lo protagonizaron.

Las consecuencias de lo ocurrido resultarían, a corto y medio plazo, lesivas para los intereses de la Corona. El comportamiento del nuevo maestre, cuyo mandato se prolongó durante casi medio siglo (1545-1592), distó de la

56 IRADIEL y CRUSELLES, 2001, I: 27-58.

57 LA PARRA LÓPEZ, 2 (Gandía, 2008-2009): 81-103.

58 MARTÍNEZ MILLÁN, 2012, II: 195-212 (de ese trabajo, el entrecomillado); LA PARRA LÓPEZ, 2012, I: 83-105.

59 Una referencia de coyuntura, además con implicaciones territoriales que interesan al caso FERNÁNDEZ ALBALADEJO, 2007: 41-64.

60 Véase, en tanto que presenta un caso con ciertas similitudes con el aquí desarrollado, e incluye además unas pocas pero autorizadas referencias bibliográficas que reflexionan sobre el mismo proceso (Elliott, Fernández Albaladejo, Molas Ribalta, Yun Casalilla), GASCÓN PÉREZ, 2014: 367-377; 369-370. 
ejemplaridad. Se valió de su posición en Montesa para intervenir en los turbios episodios de bandos nobiliarios que tantos problemas ocasionaron en la Valencia de la segunda mitad del Seiscientos, ya aludidos. Bien puede decirse que Felipe II tuvo en Galcerán de Borja una recurrente preocupación. Y, por otra parte, don Pedro esquilmó e hipotecó la Orden cuanto pudo, pues la consideró siempre un patrimonio personal del que beneficiarse él mismo junto con sus deudos. Lo hizo desde el principio de su gobierno ${ }^{61}$, y al fin le puso un precio exorbitado cuando, otra vez por motivos personales - hizo también su parte la presión a la que fue sometido por el rey-, decidió auspiciar la incorporación de Montesa al final de sus días. Para entonces, 1592, la institución que heredó la monarquía habría sufrido un grave quebranto ${ }^{62}$.

\section{BibLIOGRAFÍA}

Andrés Robres, Fernando, «De la borrascosa vida de don Pedro Luis Galcerán de Borja y su historiografía: nuevas noticias», en E. García Hernán y $\mathrm{M}^{\mathrm{a}}$ del Pilar Ryan (eds.) Francisco de Borja y su tiempo. Política, Religión y Cultura en la Edad Moderna, Valencia-Roma, Albatros Ediciones - Institutum Historicum Societatis Iesu, 2011; 711-732.

61 Sendas cartas de aquellos años, de Galcerán a Felipe (San Mateo, 15 de octubre de 1546, Monumenta Borgia I: 439-440. AGS), y de su madre - la duquesa viuda doña Francisca-, al vizconde de Evol (Guillem Ramón Galcerán de Castro-Pinós, IX vizconde de Évol, su propio hermano), (Valencia, 5 de septiembre de 1548, Monumenta Borgia VI: 662-663; de AHN, Osuna, leg. 567, original) ponen otra vez de manifiesto la percepción de patrimonio familiar que se tuvo siempre del maestrazgo. En particular la segunda, en que la siempre lamentosa duquesa viuda se queja de los costes de la operación y de lo magro de la renta: «digo, con toda verdad, que con los gastos excesivos que se offrescieron en los negocios y despachos del maestrazgo, que por haber sido tan grandes hasta agora queda mucha parte dello por pagar, y con otros voluntarios que el maestre ha hecho por su mocedad [...], y con ser el gasto de la casa tan grande en una tierra tan costada como esta, donde la necesidad destos desdichados pleitos me obliga a residir, y con no quedarle al maestre tres mil ducados del maestrazgo [cifra pretendidamente exagerada a la baja, claro está: véase nota 4] y ser esta otra hacienda tan poca como es estando de la manera que está, y con no poderse pagar lo mucho que se debe [...], cada día crezca más la necesidad; es tanta la que en esta casa se padece que ya no sé cómo me pueda valer». Los pleitos que se refieren no deben ser otros que los que sostuvo con Francisco de Borja, el primogénito de la primera esposa del duque Juan, respecto de la herencia de este y el reparto de la misma entre los Borja y Aragón y los Borja Castro-Pinós; algunas consideraciones sobre el particular recoge, desde la biografía del santo debida al padre Nieremberg, GARCÍA HERNÁN, 2012: 61-81; 65.

62 Son, todos esos, aspectos ya conocidos: remito, puesto que allí se hace referencia también a publicaciones anteriores, a ANDRÉS ROBRES, 2011: 711-732. Con solo un añadido: el IV duque bien pudo no estar al margen, ni mucho menos, de ciertas prácticas igualmente no ejemplares, junto con —o sin—, Pedro Luis Galcerán: un reciente botón de muestra, GARÉS TIMOR, 2014: 163-164. 
Andrés Robres, Fernando, «Los Borja al asalto de Montesa: prolegómenos, primer intento (1537) y gestación del definitivo», en R. Franch, F. Andrés y R. Benítez, (eds.), Cambios y resistencias sociales en la Edad Moderna. Un análisis comparativo entre el centro y la periferia mediterránea de la monarquía hispánica, Madrid, Sílex, 2014a; 295-303.

Andrés Robres, Fernando, «El maestrazgo de Montesa en 1545: la propuesta de Pedro de la Gasca», en P. Díaz, P. Martínez y Á. Soto, (eds.) El poder de la historia. Huella y legado de Javier $M^{a}$ Donézar Díez de Ulzurrun, Madrid, Servicio de Publicaciones de la Universidad Autónoma de Madrid, 2014b, I; 467-480.

Andrés Robres, Fernando, «Borja y Castro, Pedro Luis Galcerán de», Diccionario Biográfico Español, Madrid, RAH, 2010, vol. IX; 154-158.

Ardit Lucas, Manuel, «El ducat de Gandia en el mapa senyorial valencià (cap a 1540): una primera aproximació», en Santiago La Parra i Maria Toldrà (eds.) Francisco de Borja (1510-1572), hombre del Renacimiento, santo del Barroco (Actas del Simposio Internacional, Gandía, 25-27 octubre - Valencia, 4-5 noviembre de 2010), Gandia, CEIC Alfons el Vell - IIEB, 2012, I; 41-60.

Breve resolución de todas las cosas generales y particulares de la Orden y Cavallería de Montesa [1624]; manuscrito de frey Joan Borja, religioso montesiano; edición y estudio preliminar de Fernando Andrés Robres y Josep Cerdà i Ballester, València, Edicions Alfons el Magnànim, 2004.

Carrasco, Rafael, Inquisición y represión sexual en Valencia. Historia de los sodomitas (1566-1785), Barcelona, Laertes, 1985.

Callado Estela, Emilio, «Breu història dels episcopologis valencians», en Scripta: revista internacional de literatura $i$ cultura medieval $i$ moderna, 1 (Valencia, 2013); 159-172.

Cerdà i Ballester, Josep. Los caballeros y religiosos de la Orden de Montesa en tiempo de los Austrias (1592-1700), Madrid, Consejo Superior de Investigaciones Científicas (CSIC), 2014.

Corpus del Emperador Carlos V (M. Fernández Álvarez ed.), 5 vols., Salamanca, Ediciones de la Universidad de Salamanca, 1973-1981; II.

Dalmases, Cándido de, El padre Francisco de Borja, Madrid, Biblioteca de Autores Cristianos, 2002.

Fernández Albaladejo, Pablo, “"Materia” de España y "edificio” de historiografía. Algunas consideraciones sobre la década de 1540», en Materia de España. Cultura política e identidad en la España moderna, Madrid, Marcial Pons, 2007, 41-64.

Fernández Izquierdo, Francisco, La Orden Militar de Calatrava en el siglo XVI: infraestructura institucional. Sociología y prosopografía de sus caballeros, Madrid, CSIC, 1992.

Fernández Izquierdo, Francisco, «Francisco de Borja, caballero de Santiago», en E. García Hernán y $\mathrm{M}^{\mathrm{a}}$ del Pilar Ryan (eds.) Francisco de Borja y su tiempo. Política, Religión y Cultura en la Edad Moderna, Valencia - Roma, Albatros Ediciones - Institutum Historicum Societatis Iesu, 2011: 79-102. 
García Hernán, Enrique, Francisco de Borja, Grande de España, Valencia, Institució Alfons el Magnànim, 1999.

García Hernán, Enrique, «Francisco de Borja y su familia», en Santiago La Parra y Maria Toldrà (eds.) Francisco de Borja (1510-1572), hombre del Renacimiento, santo del Barroco (Actas del Simposio Internacional Gandía, 25-27 octubre - Valencia, 4-5 noviembre de 2010), Gandia, CEIC Alfons el Vell - IIEB, 2012; I: 61-81.

García Hernán, Enrique, Ignacio de Loyola, Madrid, Taurus, 2013.

Garés Timor, Vicent $\mathrm{M}^{\mathrm{a}}$, «Un avalot ab gran violència e repicament de campana. La presunta fautoría del duque de Gandía i la resistencia a los oficiales reales (1545)», en R. Franch, F. Andrés y R. Benítez, (eds.) Cambios y resistencias sociales en la Edad Moderna. Un análisis comparativo entre el centro y la periferia mediterránea de la monarquía hispánica, Madrid, Sílex, 2014; 163-172.

Gascón Pérez, Jesús, «Hijos de reyes, rebeldes y cortesanos. La difícil integración de la casa de Aragón al servicio de la Monarquía Hispánica», en R. Franch, F. Andrés y R. Benítez (eds.) Cambios y resistencias sociales en la Edad Moderna. Un análisis comparativo entre el centro y la periferia mediterránea de la monarquía hispánica, Madrid, Sílex, 2014; 367-377.

Hampe Martínez, Teodoro, Don Pedro de la Gasca (1493-1567); su obra política en España y América, Tesis doctoral, Universidad Complutense, Madrid, 1986.

Hampe Martínez, Teodoro, «Don Pedro de la Gasca, visitador general en el Reino de Valencia (1542-1545)», Estudis: Revista de Historia Moderna, 13 (Valencia, 1987), 75-98.

Hampe Martínez, Teodoro, Don Pedro de la Gasca, 1493-1567: su obra política en España y América, Palencia, Diputación, 1990.

Hermosa de Santiago, Fernando, El nuevo priorato de las Órdenes Militares. Contestación a la memoria que publicó el M. I. Sr. Dr. frey D. Pedro María Torrecilla y Navalón, del hábito de Montesa, antiguo capellán de honor de S. M. por la dicha orden y actualmente arcipreste de esta Santa Iglesia Prioral..., Madrid, Imprenta de Lezcano y Compañía, 1880.

Hernández Ruano, Javier, Justicia y sociedad en el señorío de la orden de Montesa en el siglo XVII. Tesis doctoral, Universitat de València, 2004, 2 vols.

Hernández Ruano, Javier, Poderosos pleitos. El señorío de Montesa, siglos XVIXVII, Castelló, Publicacions de la Universitat Jaume I, 2014.

Historia Cronológica de los Abades de el Real Monasterio de N. Señora de Valldigna [...]. Escrito por un monge del mismo [...]. Año MDCCL, Simat de la Valldigna, Edicions la Xara, 2004.

Iradiel, Paulino, y Cruselles Gómez, José $\mathrm{M}^{\mathrm{a}}$, «El entorno eclesiástico de Alejandro VI. Nota sobre la formación de la clientela política borgiana (1429-1503)», en M. Chiabó, S. Maddalom M. Miglia y A.M. Oliva (coords.) Roma di fronte all'Europa al tempo di Alessandro VI, Roma: Ministero per i Beni e le Attività Culturali, 2001; I: 27-58.

Keniston, Hayward, Francisco de los Cobos. Secretario de Carlos V, Madrid, Castalia, 1980. 
La Parra López, Santiago, «El ducado de Gandía y la memoria familiar de san Francisco de Borja», en Actes del II Simposi Internacional sobre els Borja. Revista Borja. Revista de l'Institut d'Estudis Borgians, 2 (Gandía, 2008-2009); 81-103.

La Parra López, Santiago, «La familia de Francisco y la violencia señorial valenciana», en E. García Hernán y $\mathrm{M}^{\mathrm{a}}$ del Pilar Ryan (eds.) Francisco de Borja y su tiempo. Política, Religión y Cultura en la Edad Moderna, Valencia - Roma, Albatros Ediciones - Institutum Historicum Societatis Iesu, 2011: 145-166.

La Parra López, Santiago, «Francisco de Borja y Gandía: la formación del cortesano», en Santiago La Parra i Maria Toldrà (eds.) Francisco de Borja (1510-1572), hombre del Renacimiento, santo del Barroco (Actas del Simposio Internacional Gandia, 25-27 octubre - Valencia, 4-5 noviembre de 2010), , Gandia, CEIC Alfons el Vell - IIEB, 2012, I: 83-105.

Laurencín, marqués de (Francisco Rafael de Uhagón), «San Francisco de Borja, caballero y comendador de la Orden de Santiago», Boletín de la Real Academia de la Historia, 22 (Madrid, 1893), 130-168.

Martí Ferrando, José, «Poder y sociedad durante el virreinato del duque de Calabria (1536-1550)», Estudis. Revista de Historia Moderna, 26 (2000), 95-112.

Martí Ferrando, José, Instituciones y sociedad valencianas en el imperio de Carlos V, Valencia, Generalitat, 2002.

Martínez Millán, José, «Francisco de Borja y la Corte», en Santiago La Parra i Maria Toldrà (eds.) Francisco de Borja (1510-1572), hombre del Renacimiento, santo del Barroco (Actas del Simposio Internacional Gandía, 25-27 octubre - Valencia, 4-5 noviembre de 2010), Gandia, CEIC Alfons el Vell - IIEB, 2012, II: 195-212.

Monumenta Borgia. Sanctus Franciscus Borgia, quartus Gandiae Dux et Societatis Jesu Praepositus Generalis Tertius; I, Madrid, Agustín Avrial, 1894; II (15301550), Madrid, Agustín Avrial, 1903; VI (1510-1572), E. García Hernán ed., Valencia, Generalitat Valenciana - Institutum Historicum Societatis Iesu, 2003.

Pons Fuster, Francisco, La Germania a Gandia i el duc Joan de Borja, Gandía, CEIC Alfons el Vell, 2008.

Postigo Castellanos, Elena, Honor y privilegio en la Corona de Castilla. El Consejo de las Órdenes y los caballeros de hábito en el siglo XVII, Madrid, Junta de Castilla y León, 1988.

Saltillo, marqués del (Miguel Lasso de la Vega y López de Tejada), Juan de Vega embajador de Carlos V en Roma (1543-1547), Madrid, Instituto de Estudios Políticos, 1946.

Samper y Gordejuela, frey Hipólito de, Montesa Ilustrada. Origen, fundación, principios, institutos, casos, progressos, jurisdicción, derechos, privilegios, preeminencias, dignidades, oficios, beneficios, héroes y varones ilustres de la Real, inclyta y nobilíssima Religión Militar de N. S. Santa María de Montesa y San George de Alfam, Valencia, Gerónymo Vilagrasa, 1669, 2 vols.

Suárez Montañés [de Corvin], Diego [soldado], Historia del Maestre último que fue de Montesa y de su hermano Felipe de Borja, la manera como gobernaron las memorables plazas de Orán y Marzaelquivir, Reynos de Tremecén y Ténez en 
Africa, siendo allí capitanes generales, uno en pos del otro, como aquí se narra. Compuesta por Diego Suárez, soldado que sirvió más tiempo de treinta años en las dichas plaças de Orán y Mazalquivir, donde inquirió y comenzó a componer estas y otras historias. Dirigido a la Ciudad de Valencia; edición parcial (a cargo de F. Guillén Robles), Madrid, Sociedad de Bibliófilos Españoles - M. Tello, 1899; edición completa (Miguel Ángel de Bunes Ibarra y Beatriz Alonso Acero, eds.), Valencia, Edicions Alfons el Magnànim, 2005.

Suau, Pierre, Historia de San Francisco de Borja, tercer general de la Compañía de Jesús (1510-1572), Zaragoza, Hechos y Dichos, 1963 [1 $1^{\mathrm{a}}$ ed. francesa de 1910$12]$.

Urzainqui Sánchez, Sergio, El asesinato de don Diego de Aragón, Segorbe, Fundación Mutua Segorbina, 2007.

Vallés Borrás, Vicent, Bases ideológicas y programa reivindicativo de la Germanía, Borriana, Ediciones histórico-artísticas, 1990.

Vallés Borrás, Vicent, La Germanía, Valencia, Edicions Alfons El Magnànim, 2000.

Recibido: $16 / 10 / 2014$

Aprobado: 17/09/2015 